\section{«PROCESO DE LA LITERATURA» PERUANA}

José Carlos Rovira Soler:

Catedrático de literatura hispanoamericana en la Universidad de Alicante. Es autor de libros, artículos y ediciones sobre autores contemporáneos (Rubén Darío, Miguel Hernández, Pablo Neruda, José María Arguedas, Juan GilAlbert) así como sobre poetas de la tradición cancioneril en la corte napolitana de Alfonso el Magnánimo, literatura novohispana, relaciones del mundo cultural italiano con la tradición hispanoamericana, siendo sus últimos libros José Toribio Medina y la fundación bibliográfica y literaria del mundo colonial hispanoamericano (2002) y Ciudad y literatura en América Latina (2005).

Mi título es evidentemente un préstamo de uno de los textos que son emblemas de la revisión de la tradición literaria en Perú: el «Proceso de la literatura», el último de los 7 ensayos de interpretación de la realidad peruana. Recordemos que el «Testimonio de parte» con el que comienza el capítulo, no quiere dejar lugar a dudas sobre el valor que le da a la palabra «proceso»:

La palabra proceso tiene en este caso su acepción judicial. No escondo ningún propósito de participar en la elaboración de la historia de la literatura peruana. Me propongo, sólo, aportar mi testimonio a un juicio que considero abierto. Me parece que en este proceso se ha oído hasta ahora, casi exclusivamente, testimonios de defensa, y que es tiempo de que se oiga también testimonios de acusación. Mi testimonio es convicta y confesamente un testimonio de parte. Todo crítico, todo testigo, cumple consciente $o$ inconscientemente una misión (...) mi misión ante el pasado, parece ser la de votar en contra. No me eximo de cumplirla, ni me excuso por su parcialidad. ${ }^{1}$

Cuando leemos por primera vez los 7 ensayos, pensamos que vamos a encontrarnos, y parcialmente así es, la palabra proceso en las acepciones no jurídicas; o sea en su valor como «transcurso del tiempo», o «conjunto de las fases sucesivas de un fenómeno natural o de una operación artificial»(RAE). Mariátegui envuelve sin embargo la palabra en su acepción judicial, aunque sepamos que va a dirigirse al transcurso de la literatura peruana.

Los 7 ensayos aparecen en 1928, dos años antes de la muerte del pensador, y se ha analizado en ellos, tras su diferente escritura en distintos tiempos, la construcción de un todo unitario que sin embargo ha sido pensado, escrito y publicado como fragmentos de una taracea de pensamiento que en esa obra, sin duda la de más aliento mariateguiano, intenta adquirir la unidad. No voy a hablar del principio de desilusión que la obra puede crearnos por el paso inexorable del tiempo sobre ella: ochenta años son muchos para que aquel «proceso» de la literatura no deba tener otras consideraciones, aparte por supuesto de otros contenidos. Me preocupa sobre todo el envejecimiento de algunas valoraciones que siguen siendo secundadas y difundidas.

No voy a hablar sobre estas cuestiones que, en esta publicación, tendrán sin duda aclaración y explicación por parte de uno de los especialistas principales en su obra, el profesor Eugenio Chang-Rodríguez, autor de la imprescindible obra Poética e ideología en José Carlos Mariátegui ${ }^{2}$, con la que tanto podemos seguir aprendiendo.

No tengo dudas sobre el valor histórico del texto con el que Mariátegui cerraba de alguna forma un ciclo de reflexión sobre la literatura peruana, un espacio teórico que se había iniciado con José de la Riva-Agüero en $1905^{3}$, y que había sido continuado y variado por José Gálvez, en 1915, y definitivamente transformado por Luis Alberto Sánchez en 19205. De alguna forma, como señaló en un incipiente trabajo Miguel Ángel Rodríguez $\mathrm{Rea}^{6}$, el texto de Mariátegui vino a continuar, variar e intentar cerrar aquel debate.

\section{¿QUÉ LEÍA O CÓMO SE FORMABA SOBRE PERÚ UN ADOLESCENTE ES- PAÑOL A MEDIADOS DEL SIGLO XX?}

Este epígrafe, como es fácil identificar, es un juego con un título de Ventura García
José Carlos Mariátegui, 7 ensayos de interpretación de la realidad peruana, Caracas, Ayaucho, 1979 , p. 149. Cito siempre a partir de esta edición.

2 Eugenio Chang Rodríguez, Poé tica e ideología en José Carlos Mariátegui, Madrid, Porrúa Turanzas, 1983.

3

José de la Riva-Agüero, $\mathrm{Ca}$ rácter de la literatura del Perú independiente, Lima, Rosay Editor, 1905.

José Gálvez, Posibilidad de una genuina literatura nacional, Lima, Casa editora M. Moral, 1915.

5

Nos referimos a su ensayo Nosotros: ensayo sobre una Literatura Nacional, tesis de Bachiller que publicó en 1920 en La Prensa de Lima, con el título Literatura peruana. Capítulo de un ensayo preliminar, los días 5,6 y 7 de agosto de 1920, pp. 1 y 2.

Miguel Ángel Rodríguez Rea, La literatura peruana en debate: 1905-1928, Prólogo de David Sobrevilla, Lima, Ediciones Antonio Ricardo, 1985.

«Proceso de la literatura» peruana JOSÉ CARLOS ROVIRA 


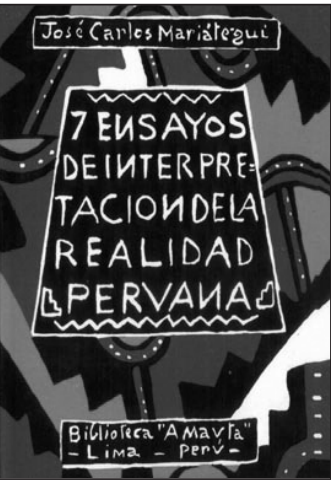

7

El título de Ventura García Calderón, donde da cuenta de sus lecturas juveniles, es ¿̇Cómo era un adolescente peruano al comenzar el siglo XX? Y está presente en Nosotros, Obra Escogida, ed. de Luis Alberto Sánchez, Lima, Edubanco, 1986, pp. 519-529. Lo antologué en José Carlos Rovira (ed.), Identidad cultural y literatura, Alicante, Instituto Gil-Albert, 1992, pp. 184-190.

\section{8}

Ramón Menéndez Pidal, et alii, Seis temas peruanos; Madrid Espasa Calpe (austral), 1960.

9

Ramón Menéndez Pidal, El padre Las Casas. Su doble personalidad, Madrid, Espasa-Calpe, 1963.

10

Una observación: no sé si don Ramón, que había leído todo, recordaría al hacer su evocación de don José Santos Chocano, la broma del gran Rubén, cuando escribió como preludio a Alma América aquel pareado que Chocano tachó: "Tal dije cuando don José Santos Chocano,/último de los Incas, se tornó castellano.

«Proceso de la literatura» peruana JOSÉ CARLOS ROVIRA
Calderón, situando yo la experiencia medio siglo después del relato del insigne peruano7. Recuerdo que esta revista intenta que se dé cuenta de algunos momentos principales de lo que llamamos Literatura peruana, a los cuatrocientos años de los Comentarios reales, convirtiendo el texto del Inca Garcilaso de la Vega en una referencia imprescindible conmemorativa (y no sólo conmemorativa): posiblemente los Comentarios tengan ya, a los cuatrocientos años de su publicación, el carácter de eje de una reflexión americana e hispanoamericana de la que no podemos prescindir para configurar sentidos, dimensiones culturales e históricas y procesos de trascendencia cultural que universalizaron aquella literatura.

Este proyecto surgió por tanto de esa conmemoración del cuarto centenario de la obra principal de Garcilaso, pero no quería presentarse como un estudio cerrado en la misma, sino como la apertura a una tradición que obtiene en ella un referente clave, y que llega a lo contemporáneo como proceso creativo. Querríamos también con él, con Gacilaso, ejemplificar una atención metodológica al Perú y su literatura que es, como sabemos, una de las grandes literaturas universales.

A veces, una conmemoración nos debe llevar a intentar un estado de la cuestión, para lo que recuerdo un referente muy negativo, con el que voy a empezar.

Narro una conmemoración acaecida en España en los trescientos cincuenta años de la publicación de los Comentarios reales. Está contenida en un volumen que se titula Seis temas peruanos ${ }^{8}$, con el subtítulo significativo de "Conferencias pronunciadas en la embajada del Perú en España», y que publicó la Colección Austral de Espasa-Calpe el 3 de diciembre de 1960, un año después de que se acogiera en la representación diplomática aquella conmemoración que se realizó exactamente entre el 12 de noviembre y el 10 de diciembre de 1959, durante los jueves de cada semana.

Firmaban aquel volumen Ramón Menéndez Pidal, Victorio Macho, el Marqués de Lozoya (o sea, Juan de Contreras y López de Ayala); José María Pemán, Gregorio Marañón y Eugenio Montes («los más ilustres de España», como dice el Marqués de Lozoya, excluyéndose de los ilustres modestamente él mismo, al comienzo de su conferencia). Lo prologaba Manuel Cisneros, embajador del
Perú, quien explicaba que faltaba un séptimo conferenciante, José María de Cossío, que apoyó la iniciativa pero que no quiso intervenir porque no conocía Perú. La verdad es que, leyendo en la actualidad esas conferencias, lo alegado por Cossío parece que era importante ya que tres de los seis conferenciantes (el escultor Victorio Macho, el Marqués de Lozoya y Eugenio Montes) crean una guía turística, memorial e imperial sobre el Cuzco, Macchu Picchu y Lima, en donde el Inca no aparece por casi ninguna parte; Gregorio Marañón nos sorprende con su «Vida y andanzas de Pablo de Olavide» que justifica porque, en Lima, habló hace cuatro años del «mestizo ungido por un nombre mágico», dice, refiriéndose a Garcilaso, y por ese motivo va a hablar ahora del dieciochesco Olavide.

Quedan Menéndez Pidal y Pemán como exclusivos conferenciantes conmemorativos. De don Ramón, en 1959, poco tenemos que decir. Mi respeto a su figura me hace doloroso siempre comentar algunos de sus textos increíbles. Tenía 90 años y le quedaban nueve de vida. Se aprestaba a publicar un libro que apareció en 1963 titulado El padre Las Casas. Su doble personalidad ${ }^{9}$, un libro que hace años describí no como obra de don Ramón, sino de Robert Louis Stevenson. De hecho parece que aprovechó aquella conferencia para anticipar lo que estaba escribiendo.

Comienza en cualquier caso su conferencia, titulada «La moral en la conquista del Perú y el Inca Garcilaso de la Vega», evocando su viaje a Perú, sus cuarenta días limeños, del lejano 1905, cuando entre otros conoció a Ricardo Palma, a José de la Riva Agüero, a José Santos Chocano, del que aprendió aquello de «la sangre es española e incaico es el latido» ${ }^{10}$. Luego deja los recuerdos de aquel viaje y nos anuncia que va a hablar de la Conquista del Perú y «de cómo el Inca Garcilaso apreció esa conquista».

Las primeras tres cuartas partes de la conferencia son un análisis sobre el Padre Las Casas y sus posiciones sobre la conquista y sobre las riquezas del Perú concretamente. Su debate con Francisco Vitoria va plagando de adjetivos negativos la imagen del dominico: su ambición, su egolatría, su miedo a ir como obispo del Cuzco, su erróneo proceder como obispo de Chiapas, su doble personalidad... páginas y páginas que se desgranan en una conferencia en la que, si hubiésemos asistido a ella, probablemente estaríamos pensando que 
a ver cuándo entra en materia. Lo hace en las cuatro páginas finales, donde contrapone la visión destructiva de la conquista que analiza en Las Casas a la visión integradora de El Inca, que verá males, incluso a veces hasta crímenes, pero que no achacará más que a los que los realizan y nunca a la Monarquía española, de la que no discute su derecho sobre las Indias:

Una vez consumada la conquista, olvidadas las fieras guerras y rebeliones subsiguientes, surge en la mente de Garcilaso una construcción histórica ideal, opuesta a la utopía jurídica de Las Casas. Mientras Las Casas exalta a los indios atropellando toda mesura en el encomio y odiaba furiosamente a los españoles, Garcilaso, ecuánime, idealiza el imperio inca sin cometer excesos comparativamente intolerables, y tiende un velo sobre las imperfecciones de la conquista, dejando ver sólo la parte grandiosa del suceso histórico. (p. 37)

Ramón Menéndez Pidal mantiene su homenaje al Inca en el interior del desconcierto para el lector que provoca su más amplio ataque a Las Casas, que no era el motivo de su conferencia y, sin embargo, sí lo fue, pero mantiene el tono reflexivo del que siempre solía hacer gala.

El otro autor que dedica su conferencia al Inca es José María Pemán, que resulta como casi siempre un ejemplo de graciosa retórica imperial. Su conferencia se llama «El Inca Garcilaso de la Vega, fruta nueva del Perú», frase que el propio Inca, en la dedicatoria de su Historia general del Perú, atribuía a Felipe II ante su traducción de los Diálogos de amor de León Hebreo.

Comienza Pemán afirmando que el Inca «es expresión y reflejo típico de los valores de la obra de España en América» (p. 75). Habla de que la conquista fue el ejemplo principal de la formación del «Orbis Christianum». Cita la obra de Bernal Díaz del Castillo, al que llama «soldadote de pocas letras», y habla de su narración civilizadora, para afirmar que «Hasta el soldado éste, un tanto iletrado, llegaba allí pretendiendo dar a sus mandobles, a sus tajos y a sus arcabuzazos, una trascendencia metafísica»(p. 77). Tras un recorrido civilizador sobre la presencia española en América, aborda la traducción de los Diálogos de amor, el episodio en el que el rey afirmó que eran «fruta nueva del Perú», para afirmar que el rey sabía que aquel libro era esto, la obra de un «criollo», dice, «que por su sangre materna tocaba todavía las nieblas precolombinas y que por su pluma tocaba ya la plenitud europea del Renacimiento» (p. 79).

Máxima expresión inequívoca el Inca de «los valores hispánicos», «de los valores de nuestra historia en América», de la armonía del ser español...y, a partir de aquí, tras una larga divagación en la que La Araucana significa la universalidad de dar protagonismo al vencido, tras tratar el teatro americano de Lope de Vega, para lo que recurre a audaces comparaciones con «angelitos negros» (bolero popularizado por Antonio Machín, al que Pemán que debía tener poco oído o conocimiento musical llama «tango gangoso»), recurre a otro ejemplo musical para explicar el castizo españolismo como síntesis de universalidad, para lo que narra que siempre llevamos a los extranjeros a que vean nuestro casticismo en La verbena de la paloma, donde la gorrita que llevan los chulos es inglesa y las mujeres lucen «el mantón de Manila», que, recalca textualmente Pemán, «que ya dice su mismo nombre que es de Manila»...

Resulta a veces difícil seguir la gracia gaditana de José María Pemán, que se convierte en chiste fácil. Lo parecen incluso sus metáforas, que a continuación abordan una nueva síntesis de la Hispanidad, en la que va a situar la obra del Inca, definiéndolo así: «ni es indigenismo puro ni europeísmo calcado sino que es toda la exuberancia de la selva virgen metida en la discreta y racional medida del Partenón de Atenas» (p. 91), para, tras un cúmulo de divagaciones de época en la que destaca la creación del «Derecho de Indias», terminar actualizando la obra del Inca, dándole un sentido contemporáneo exactamente así:

Ahora hay también una luz incansablemente encendida, con satánico desvelo, en los laboratorios donde se desintegra el átomo o se conspira contra las bases morales de la sociedad. Y yo os digo a todos vosotros, diplomáticos, escritores, académicos, catedráticos, que me estáis escuchando esta tarde: no apaguéis vuestras luces hasta ver quién acaba primero su tarea, si los que están trabajando para la guerra y la muerte o los que están trabajando para aquel orden integrador que tan entrañablemente sentía el Inca Garcilaso, y que reclama un nuevo Derecho planetario puesto radicalmente al servicio y de la paz y la confraternidad entre los hombres. (p. 97)

Así se conmemoraba al Inca Garcilaso en la España de hace cincuenta años. He dejado

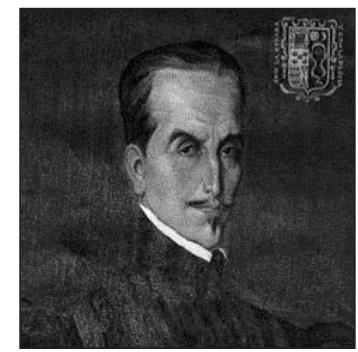

Inca Garcilaso de la Vega. 


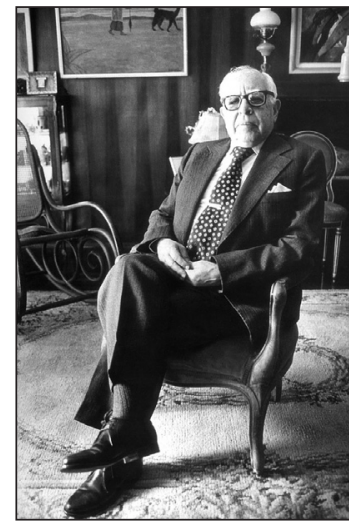

Luis Alberto Sánchez.

11

La noción de modernidad tiene que ser afrontada en cualquier caso desde los espacios políticos que se refieren a ella. Como resumen muy breve diré que la estructura del país aparecía vinculada a las estructuras económicas del pasado y que la estructura social aparecía fracturada por una gran población indígena desposeída y una oligarquía terrateniente que era heredera de los grupos sociales que detentaron siempre el poder En medio, una burguesía débil y un incipiente proletariado. En los terrenos políticos de la «modernidad», la posición que encarnará Mariátegui tiene que ver con una noción de modernidad asociada a un programa de transformación revolucionario y socialista, pero la modernidad es una perpleja instancia que se intenta alcanzar desde otros predicados ideológicos: el liberalismo o la socialdemocracia aprista.

«Proceso de la literatura» peruana JOSÉ CARLOS ROVIRA muchas perlas esparcidas por los otros escritos turísticos e imperiales que conforman el volumen. A fin de cuentas, lo que he propuesto hasta aquí no es más que una entrada que me parece casi humorística al tema de nuestro monográfico, que se celebra cincuenta años después de aquel y a cuatrocientos años de los Comentarios reales. Es evidente que el Inca va a ser tratado en este número como referencia de la formación de una tradición literaria que es muy amplia y muy rica. Pero querría recoger algunas reflexiones que todavía me parecen de necesario recorrido antes de su comienzo.

\section{HISPANISMO, COLONIALISMO, INDI- GENISMO, LITERATURA NACIONAL}

Mi segundo enunciado nos sitúa ante cuatro términos que el adolescente, o algo más mayor, el joven español que quiera adentrase en la literatura peruana, hará bien en plantearse. Como Francisco José López Alfonso ha dado cuenta en sus libros, y en el artículo aquí publicado, de la trascendencia de este debate, les resumo por mi parte el manifiesto cansancio que me produjo, en su día, intentar entender una discusión de comienzos de siglo $\mathrm{XX}$ de la que antes he mencionado algunos textos principales.

Nos era muy difícil entender el indigenismo, por ejemplo, a los que nos habíamos formado en la mistificación imperial de la hispanidad. Lo conté una vez como experiencia personal. Para mí fue la lectura de José María Arguedas la que me adentró en la cuestión del indigenismo, y lo hizo en un terreno estético. Nos resultaba muy difícil adentrarnos en un debate que, en todo caso, intentaba conformar una identidad nacional de la literatura.

El problema esencial de la literatura peruana, como el de todas las literaturas de América, venía determinado por la relación con el pasado previo a la Independencia y, en el caso peruano, como en el mexicano, de una forma acuciante, por la relación que se establecía con el mundo previo a la colonia, con el mundo prehispánico. Determinar la relación de lo que llamaban Literatura peruana con la colonial y la prehispánica se convierte, a comienzos de siglo XX, en uno de los puntos cruciales de un debate que determina el mundo intelectual.

El siglo XIX había empezado a nacionalizar la tradición colonial como parte de identificación de lo peruano. Conocemos el papel que las literaturas nacionales, surgidas tras la independencia, confieren al pasado colonial como parte de la expresión literaria del país y de su identidad. En el caso de Perú, la propia conciencia de su determinación histórica, la condición virreinal y todos sus mitos conexos, y la clase dirigente que sucedió a la que detentaba los poderes en el virreinato, que a fin de cuentas era la misma, crearon una tendencia a asumir la tradición colonial como propia, sin más ruptura que el hecho político de la independencia. Pero las crisis sociales del tiempo posterior a la independencia favorecieron aún más esa apropiación del pasado como «nostalgia virreinal», que bien identificó Mariátegui en sus 7 ensayos (cf. «El problema de la tierra»).

Esta encrucijada está actuando a comienzos de siglo y la determina un eje social y cultural que se plantea la modernidad como objetivo, y que quiere saldar cuentas con el pasado, o incorporarlo a la misma modernidad ${ }^{11}$.

Surgen tendencias culturales que reivindican el pasado desde otras perspectivas y matices. Si quisiésemos buscar dos polos diferenciados ampliamente en sus objetivos, pero muy próximos quizá en análisis, tendríamos que recordar la perplejidad que nos produce leer algunos textos que informan el debate literario sobre la colonia en los primeros treinta años del siglo XX.

Me referiré a ello:

1. La conceptualización de los «hispanistas». La tesis de José de la Riva-Agüero, $\mathrm{Ca}$ rácter de la literatura del Perú independiente, publicada en 1905, plantea radicalmente la dependencia de lo que se considera literatura peruana respecto de la literatura española. Recordemos la aseveración principal de RivaAgüero:

La literatura peruana forma parte de la castellana. Esta es la verdad inconcusa, desde que la lengua que hablamos y de que se sirven nuestros literatos es la castellana. La literatura del Perú, a partir de la Conquista, es literatura castellana provincial, ni más ni menos que la de las islas Canarias o la de Aragón o Murcia, por ejemplo, puesto que nada tiene que ver con la literatura, la dependencia o independencia policía de la región donde se cultiva. (p. 220)

Esta tesis de la identidad con la literatura española conlleva una valoración negativa de la tradición imitativa colonial: 
¿A qué se reduce pues la literatura colonial? A sermones y versos igualmente infestados por el gongorismo y por bajas adulaciones, y a la vasta pero indigesta erudición de Diego León Pinelo, Espinosa Medrano, Menacho, Llano Zapata, Bermúdez de la Torre, Peralta y Bravo Lagunas: literatura vacía y ceremoniosa, hinchada y áulica, literatura chinesca y bizantina, a la vez caduca e infantil, con todos los defectos de la niñez y de la decrepitud, interesante para el bibliófilo y para el historiador pero inútil y repulsiva para el artista y para el poeta. (p. 76)

En su conceptualización hay además una negación explícita del pasado prehispánico como informante o integrante de la tradición literaria. Sobre el mundo indígena repite conceptualmente sobre todo las afirmaciones de Marcelino Menéndez Pelayo $^{12}$, a quien cita como testimonio de autoridad junto a otros españoles, cuando está hablando de la americanización de la literatura:

El sistema que para americanizar la literatura se remonta hasta los tiempos anteriores a la conquista, y trata de hacer revivir poéticamente las civilizaciones quechua y azteca, y las ideas y los sentimientos de los aborígenes, me parece el más estrecho e infecundo. No debe llamársele americanismo sino exotismo. Ya lo han dicho Menéndez Pelayo, Rubió y Lluch y Juan Valera: aquellas civilizaciones o semicivilizaciones ante-hispanas murieron, se extinguieron, y no hay modo de reanudar su tradición, puesto que no dejaron literatura. Para los criollos de raza española son extranjeras y peregrinas, y nada nos liga con ellas; y extranjeras y peregrinas son también para los mestizos y los indios cultos, porque la educación que han recibido los ha europeizado por completo. (p. 227)

El tiempo en el que considera que vive es además el de una «incipiente literatura peruana» que, para Riva-Agüero, debe «conservar el legado de la tradición española». La incipiente literatura ha entrado en una negativa actitud de imitación hacia el mundo cultural francés, imitación que la está empobreciendo, mientras que lo que debe hacer es mirar a los grandes modelos europeos. Las posiciones de crítica literaria contemporánea, su rechazo al inicial indigenismo de Mariano Melgar, o su crítica ideológica a la poesía de Manuel González Prada, y a otros contemporáneos, son elementos que no puedo tratar aquí, donde sólo propongo una reseña de sus posiciones más importantes y centrales en relación a lo español y lo indígena.
2. Matices y transformaciones: Hay dos contribuciones ya mencionadas que construyen una matización y variación de las tesis de Riva-Agüero. Me refiero al libro de José Gálvez (Posibilidad de una genuina literatura nacional) aparecido en 1915 y, sobre todo, a los trabajos que Luis Alberto Sánchez publica a partir de 1920.

3. La preocupación principal de Gálvez es fijar lo nacional, tras la aceptación de los parámetros de imitación en los que ha surgido y se ha desarrollado la literatura en Perú. La adaptación de los modelos europeos ha estado carente de originalidad «al desdeñar lo propio y empequeñecerlo» (p. 43). Sólo la fusión de lo propio, de la tradición, permitirá vincularse al «sentido universal literario»y, para ello, lo propio serán los «temas nacionales», por lo que propone una mirada al mundo indígena, una incorporación de «la raíz histórica del legado indígena en su imponente grandeza, en su misteriosa y enorme vaguedad legendaria», pero considerando el mundo del pasado precolombino como algo acabado (p. 16) que, sin embargo, abre raíces sentimentales hacia el presente: Mariano Melgar, por ejemplo, como gran comienzo de originalidad en su fusión de la clasicidad con lo indígena. Un debate sobre la literatura de lo criollo y la literatura criolla anima la presencia del criollismo como una forma de identidad nacional, sin desarraigarse de la tradición hispánica.

4. Luis Alberto Sánchez: en 1928, el mismo año en el que Mariátegui publicará los 7 ensayos, aparece el primer volumen de La literatura peruana. Derrotero para una historia espiritual del Perú de Luis Alberto Sánchez ${ }^{13}$, donde plantea la presencia prehispánica como un antecedente necesario para explicar la literatura nacional, cuestión que ya había abordado en Nosotros: ensayo sobre una literatura nacional, tesis de bachillerato de Sánchez que apareció en La Prensa de Lima los días 5, 6 y 7 de agosto de 1920 con el título Literatura peruana. Capitulo de un ensayo preliminar, donde ya afirma la tradición quechua como raíz de la literatura peruana. En palabras de Antonio Cornejo Polar: «Es mérito indiscutible de Sánchez el haber ganado para la historia de la literatura peruana todo un vasto período, el prehispánico, como parte constitutiva de un proceso que resulta inexplicable sin ese antecedente» ${ }^{14}$. En la fijación de esta idea, está la vuelta hacia un pasado que, desde la tradición de la oralidad, se puede recuperar

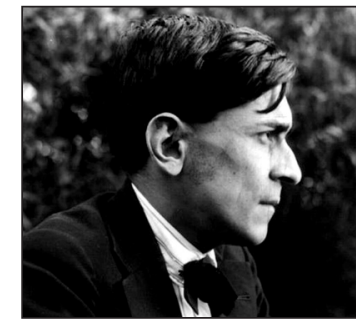

José Carlos Mariátegui.

12

Recordemos: «La poesía americana de que vamos a tratar no es de las elegías del rey de Tetzcuco, Netzahualcoyolt, ni la del Ollantay, drama quechua no anterior al siglo XVIII, sino la que llevaron a América los colonos españoles y conservan sus descendientes. Si algo de americanismo primitivo llegó a infiltrarse en esta poesía (lo cual es muy dudoso), sólo en este sentido podrán tener cabida tales elementos bárbaros y exóticos en un cuadro de la literatura hispano-americana, la cual, por lo demás, ha seguido en todo las vicisitudes de la general literatura española [...]. Esto no excluye gran originalidad en los pormenores; pero el fundamento de esta originalidad, más bien que en opacas, incoherentes $y$ misteriosas tradiciones de gentes bárbaras o degeneradas, que para los mismos americanos de hoy resultan mucho más extrañas, menos familiares y menos interesantes que las de los asirios, los persas o los egipcios; ha de buscarse en la contemplación de las maravillas de un mundo nuevo, en los elementos propios del paisaje, en la modificación de la raza por el medio ambiente, y en la enérgica vida que engendraron, primero el esfuerzo de la colonización y de la conquista, luego la guerra de separación, y, finalmente, las discordias civiles». Marcelino Menéndez Pelayo, Historia de la poesía hispano-americana, Madrid, CSIC, 1948, p. 10.

13

Luis Alberto Sánchez, La literatura peruana. Derrotero para una historia espiritual del Perú, Lima, Ed. Ediventas, 1966, $3^{a}$ ed.

14

Antonio Cornejo Polar, La formación de la tradición literaria en el Perú, Lima, Centro de Estudios y Publicaciones, 1989, p. 118.

«Proceso de la literatura» peruana JOSÉ CARLOS ROVIRA 


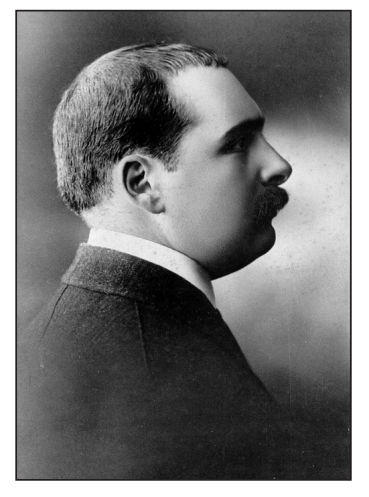

15

Antonio Conejo Polar, op.cit., p. 130.

16

Corpus textual que tiene en la actualidad la muy útil antología Edmundo Bendezú Aybar, (ed.), Literatura quechua, caracas, $\mathrm{Bi}$ blioteca Ayacucho, 1980.

17

E.W. Middenorf, Dramattische und lyrische Dichtungen der Keshua Sprache, Leipzig, F.A. Brochaus, 1891.

18

Adolfo Vienrich, Azucenas quechuas, Tarma, La Aurora, 1905; y Fábulas quechuas, Tarma, La Aurora, 1906. Cf. El análisis de Cornejo Polar, op.cit., pp. 125-126.

«Proceso de la literatura» peruana JOSÉ CARLOS ROVIRA y que será una de las bases de la escritura y de lo nacional.

5. Mariátegui: sin embargo, sorprende la debilidad del planteamiento de Mariátegui sobre la literatura prehispánica en los 7 ensayos; sorprende en quien estaba intentando fundar una tradición cultural indígena y, sin embargo, afirmaba que:

La civilización autóctona no llegó a la escritura y, por ende, no llegó propia y estrictamente a la literatura, o más bien, ésta se detuvo en la etapa de los aedas, de las leyendas y de las representaciones coreográficoteatrales. La escritura y la gramática quechuas son en su origen obra española y los escritos quechuas pertenecen totalmente a literatos bilingües... (p. 153)

Por eso mismo, el veredicto de literatura nacional parece irrenunciablemente español en sus orígenes:

La literatura nacional es en el Perú, como la nacionalidad misma, de irrenunciable filiación española. Es una literatura escrita, pensada y sentida en español, aunque en los tonos, y aun en la sintaxis y prosodia del idioma, la influencia indígena sea en algunos casos más o menos palmaria e intensa. (p. 153)

Un postmariateguiano de indudable rigor como Antonio Cornejo Polar tuvo que platearse el problema, cuando analizaba que el maestro intentó fundar precisamente un panorama cultural en el que el tradicionalismo consideraba el pasado prehispánico como prehistoria, mientras el espíritu revolucionario de su época «reasume la tradición nacional íntegra y subraya la importancia de lo nativo» ${ }^{15}$, para afirmar lo paradójico de «El proceso de la literatura», donde parece incoherente que establezca que el límite de la literatura peruana sea la irrupción de la escritura en español, con lo que margina de su historia tanto el proceso anterior a la conquista como las manifestaciones modernas de la oralidad indígena» (p. 131).

Plantea a continuación Cornejo una forma de salida de la contradicción en la que sin duda Mariátegui está incurriendo: él mismo relativizaba el concepto de literatura nacional y, adentrándonos en su texto, podemos llegar a partir de este problema a la interpretación de la literatura peruana como una literatura, dice Cornejo, «no orgánicamente nacional». Se fija en otro fragmento de «El proceso de la literatura», cuando dice: «El dualismo que- chua-español del Perú no resuelto aún, hace de la literatura nacional un caso de excepción que no es posible estudiar con el método válido para las literaturas orgánicamente nacionales, nacidas y crecidas sin la intervención de una conquista», y reafirma la idea del Perú como una nación conflictiva, en formación, desgarrada por la conquista en relación al hecho originario, para lo que recuerda otra cita de «Regionalismo y centralismo», otro de los 7 ensayos: «En el Perú el problema de la unidad es mucho más hondo, porque no hay aquí que resolver una pluralidad de tradiciones locales o regionales sino una dualidad de raza, de lengua y de sentimiento, nacida de la invasión y conquista del Perú autóctono por una raza extranjera que no ha conseguido fusionarse con la raza indígena, ni eliminarla ni absorberla».

Afirma Cornejo a partir de aquí que, para Mariátegui, «lo nacional no es, entonces, un punto de partida, algo ya resuelto por el curso de la historia, sino un proyecto y hasta una utopía» (p. 132), que cumpliría el período final de la periodización establecida por Mariátegui de la literatura nacional como final del proceso que precedió, integrado por la literatura colonial y cosmopolita.

Al margen de esta cuestión determinativa de la literatura nacional, hay un problema mucho más sencillo que quizá sea el que tengamos que recorrer. ¿Dónde situamos la existencia de un corpus textual en quechua que permita una reivindicación de ese pasado? ${ }^{16}$. Los antólogos contemporáneos de la literatura quechua hacen un recorrido por los textos históricos con fragmentos literarios quechuas de Juan de Betanzos (1551), Pedro Sarmiento de Gamboa (1572), Cristóbal de Molina (1573), Blas Valera (1578), Felipe Huamán Poma de Ayala (1585), Inca Garcilaso de la Vega (1593), Francisco de Ávila (1598) y Juan de Santa Cruz Pachacuti Yamki Salcamaygua (1613).

Por otra parte, la primera gran recopilación textual es la del lingüista alemán E.W. Middendorf, que se publicó en Leipzig en $1891^{17}$, y la primera peruana, de textos procedentes de la oralidad, es la muy curiosa $A z u-$ cenas quechuas, obra emérita del farmacéutico Adolfo Vienrich, publicada en la localidad andina de Tarma en 1905, y continuada en 1906 por Apólogos quechuas, obras en las que restos de la textualidad del pasado se unen a la continuidad de la escritura quechua del presente ${ }^{18}$. 
Lo que parece evidente es que el estado de la textualidad quechua, e inca, no era en los años 20 el que empezará a ser en el decenio siguiente, con datos inaugurales como la $\mathrm{Li}$ teratura Inca (1938) de Jorge Basadre ${ }^{19}$, o el trabajo de recuperación, entre el presente y el pasado, de José María Arguedas, iniciado por Canto Kechwa también en $1938^{20}$.

Estos datos nos llevan a afirmar que Mariátegui lo que hizo sobre la literatura inca e indígena es no hablar de lo que no conocía o no podía conocer, lo que crea ese efecto extraño en su «proceso de la literatura», obra en la que necesariamente quería desembarazarse de la lección de un maestro como José de la RivaAgüero, el maestro de la tradición hispanista en el Perú. Sobre la tradición colonial, recordemos también las posiciones de Mariátegui:

La primera etapa de la literatura peruana no podía eludir la suerte que le imponía su origen. La literatura de los españoles de la Colonia no es peruana; es española. Claro está que no por estar escrita en idioma español, sino por haber sido concebida con espíritu y sentimiento españoles. Gálvez, hierofante del culto al Virreinato en su literatura, reconoce como crítico que «la época de la Colonia no produjo sino imitadores serviles e inferiores de la literatura española, y especialmente la gongórica de la que tomaron sólo lo hinchado y lo malo y que no tuvieron la comprensión ni el sentimiento del medio, exceptuando a Garcilaso, que sintió la naturaleza y a Caviedes que fue personalísimo en sus agudezas y que en ciertos aspectos de la vida nacional, en la malicia criolla, puede y debe ser considerado como el lejano antepasado de Segura, de Pardo, de Palma y de Paz Soldán». (p. 154)

La cita de la Posibilidad de una genuina literatura nacional de José Gálvez, obra de 1915, y la coincidencia con Riva-Agüero en la valoración de la literatura colonial como literatura española, sólo adquiere un matiz diferente cuando a continuación Mariátegui enfoca la obra de Garcilaso:21

Garcilaso, sobre todo, es una figura solitaria en la literatura de la Colonia. En Garcilaso se dan la mano dos edades, dos culturas. Pero Garcilaso es más inka que conquistador, más quechua que español. Es también, un caso de excepción. Y en esto residen precisamente su individualidad y grandeza. Garcilaso nació del primer abrazo, del primer amplexo profundo de las dos razas, la conquistadora y la indígena. Es, históricamente, el primer "peruano» si entendemos la «peruanidad» como una formación social, deter- minada por la conquista y colonización españolas. Garcilaso llena con su nombre y su obra una etapa entera de la literatura peruana. Es el primer peruano, sin dejar de ser español. Su obra, bajo su aspecto histórico-estético, pertenece a la épica española. Es inseparable de la máxima epopeya de España: el descubrimiento y la conquista de América». (p. 154)

Mariátegui mantiene aquí un difícil equilibro, o una contradicción que, por un lado lo lleva a fundar en Garcilaso el ser de la peruanidad y, por otro, a seguir afirmando el carácter español de su obra. Es destacable el escaso conocimiento de la literatura colonial que demuestra. Ni tan siquiera presta atención a indicaciones de Riva-Agüero, que en el apéndice a su libro de 1905 reconoció ya su olvido, ente otras cosas, de la lírica colonial salvando, a través de Menéndez Pelayo, el «Discurso en loor de la poesía» y la «Epístola de Amarilis a Belardo»22. Creo que Mariátegui demuestra poco conocimiento del proceso literario peruano en su historia y aventura una opinión tajante que tiene su centro expresivo en su «Colonialismo supérstite», la tesis tercera del «Proceso de la literatura», donde lanza su visión de los tres períodos de la literatura peruana (colonial, cosmopolita y nacional), y en algunas reflexiones esenciales, como su rescate de Ricardo Palma del colonialismo en el que varios, como Riva-Agüero, lo situaban.

Pero el proceso de la literatura, pienso ahora, no fue el análisis de la historia colonial, o prehispánica, o el criollismo (que razones de tiempo y espacio me han impedido reflejar). Creo que hoy, en la revisión de aquellos espacios polémicos, queda sobre todo una noción del proceso literario que me interesa destacar y que de alguna forma abre el sentido del encuentro que vamos a hacer. No he destacado suficientemente que donde se clausura de una forma absoluta el tema del futuro de la literatura y la imitación es en Mariátegui, precisamente al anunciar el presente. Veamos rápidamente el problema.

José de la Riva-Agüero, tras su afirmación hispanista, tras criticar el afrancesamiento de la literatura del Perú independiente, tras insistir en la necesidad de no abandonar el tronco común español, plantea como objetivo, para huir de la monotonía del criollismo, para abandonar los vaivenes de las modas, «estudiar a los autores clásicos de las literaturas extranjeras» como fuente de una nueva imitatio basada en múltiples modelos, incluso
19

Jorge Basadre, La literatura Inca, Paris, Desclée de Brouwer 1938. En la Biblioteca de Cultura Peruana de Ventura García Calderón.

20

José María Arguedas, Canto Kechwa, Lima, Compañía de Impresiones y Publicaciones, 1938.

21

Riva-Agüero enfoca a Garcilaso, en nota, dentro de las crónicas históricas que, "aunque por lo general no fueran en la mente de sus autores obras literarias, tienen, quizá por lo mismo, una ingenuidad y una sencillez encantadoras»; habla de las crónicas «deliciosas» de Garcilaso, pero las excluye, junto a otras "porque no alcanzan a alterar el aspecto de las letras de la Colonia» (p. 15-16).

22

Estas dos obras, esenciales para el proceso literario peruano han tenido una excelente edición crítica reciente con una introducción esencial: Clarinda y Amarilis, Discurso en Loor de la poesía. Epístola a Belardo, ed. de Raquel Chang-Rodríguez, Lima, Pontificia Universidad Católica del Perú, 2009

«Proceso de la literatura» peruana JOSÉ CARLOS ROVIRA 
en los más selectos de la tradición contemporánea europea, con un consejo con el que casi cierra sus reflexiones:

Debemos aprender pero no repetir servilmente; asimilar, pero no copiar; aclimatar, pero no reflejar sin crítica ni propósito, como lo hemos venido haciendo en todo el curso de nuestra historia. Sólo por esta labor de selección de imitaciones podemos suplir la originalidad que nos falta y crearnos en el concierto de la civilización universal un lugar modesto pero digno, exento de pretensiones prematuras y de ridiculeces pueriles. $Y$ ¿quién sabe si en ella no se oculta el germen de la originalidad para lo por venir? (p. 271)

José Gálvez, al matizar a Riva-Agüero en pos de una «genuina literatura nacional» plantea, más que la imitación, la adaptación de los modelos europeos que deben ser hechos carne «en nuestro espíritu» y producir frutos «modificados» a través de «nuestro temperamento», para que programáticamente debamos asumir que:

No desconozco la fuerza de la imitación y le doy toda su importancia, pero creo que cabe dentro de la individualidad de cada artista atender más al ambiente que nos rodea, a la tradición que nos cobija, al legado de razas y de historia que pesa sobre nosotros. Si hay posibilidad de que tengamos literatura ¿por qué no cabe que sea fruto en parte del medio y del factor histórico? (p. 19)

Luis Alberto Sánchez, que reconoce el pasado como el de una imitación necesaria, critica la postura imitativa hacia el futuro que plantea Riva-Agüero, también en la cancelación de los elementos indígenas cuya posibilidad está construyendo:

Riva Agüero [...] habla de la imitación y dice que ella moldeará nuestra futura originalidad literaria. La paradoja no puede ser más audaz, sin embargo, añade, esa imitación no es copia sino asimilación; sólo que no se comprende por qué deslinda, como exótico, el elemento indígena, ni por qué no hemos de poder constituir los latinoamericanos nuestra literatura, a fuerza de hurgar la propia historia, la conciencia propia, y a fuerza de imaginar el porvenir. Como disculpa a nuestras muchas imitaciones y plagios, pase la afirmación de Riva-Agüero. Como orientación, jamás ${ }^{23}$.

En 1928, José Carlos Mariátegui sacaba a la literatura peruana de este debate y lo hacía no sólo con la consideración de la literatura peruana como una literatura «no orgánicamente nacional» por la compleja realidad social y racial que debía asumir, sino, sobre todo, por la mirada a los próximos y a los contemporáneos que realiza en su «Proceso de la literatura», mirada que no constituye sólo la parte más amplia, sino la más consistente de la obra: allí está la propuesta de lectura de Palma fuera del colonialismo en el que algunos seguían situándolo, allí su reivindicación de Manuel González Prada, sus nuevas lecturas de Melgar, o de la limitación española de Chocano, su reivindicación de Valdelomar, de Eguren, de Alberto Hidalgo, de Magda Portal, de Alberto Guillén, de Alcides Spelucín, o aquella nueva propuesta para el indigenismo actuante en su contemporaneidad que anticipa tiempos esenciales de la narrativa peruana, o aquel nombre que destaca en el panorama como César Vallejo en quien literalmente funda la grandeza de la nueva creación que, tras superar la etapa colonial, empieza a separarse también de la cosmopolita para entrar en la nacional a través de los nuevos modelos. Sus contemporáneos, encerrados en un debate todavía teórico sobre la imitación, no tuvieron tiempo, o al menos no tuvieron la intensidad de su mirada, a excepción de Luis Alberto Sánchez que la estaba iniciando.

Creo que la gran lección del «proceso de la literatura» es su capacidad de anticipar en 1928 un tiempo literario que iba a universalizar y a dotar de profunda originalidad a la literatura peruana. Los otros debates quedan ahí, comprimidos por un debate en la historia, mientras Mariátegui definió lo nuevo con la belleza con la que cierra su estudio, cuando, hablando de la imitación todavía imperante hacia los «decadentismos occidentales», anuncia un tiempo en el que «bajo este flujo precario, un nuevo sentimiento, una nueva revelación se anuncian. Por los caminos universales, ecuménicos, que tanto se nos reprochan, nos vamos acercando cada vez más a nosotros mismos». 